\title{
Menopause: an important milestone in women's health
}

\author{
Seng Bin $\underline{\text { Ang }}{ }^{1}$, mBBs, mMed, Choon How $\underline{H o w}^{2}$, MMed, FCFP
}

\begin{abstract}
Madam Tan, a 48-year-old woman, was brought by her daughter for confirmation of menopause. She has not had menses for three months and has been experiencing hot flushes five times a day. She also complains of disturbances in her sleep and feels hot throughout the night, which is different from the hot flushes experienced in the day. Her daughter has been affected by Madam Tan's frequent mood swings and outbursts, and would like you to confirm if Madam Tan is menopausal through a blood test.
\end{abstract}

\section{HOW RELEVANT IS THIS TO MY PRACTICE?}

Menopause is a natural process that all women will go through. In the absence of other causes of menstrual disturbances, menopause is defined as the permanent cessation of menstrual period for 12 consecutive months. Hence, the final menstrual period is determined retrospectively, and laboratory tests are required only if secondary causes are suspected. The average age of natural menopause in Singapore is 49 years old, with one study reporting that more than $90 \%$ of women reached menopause at the age of 53 years. ${ }^{(1,2)}$ With $29.2 \%$ of our population aged between 45 and 65 years old in the year 2012, coupled with the fact that about $50 \%$ of women going through menopause will experience some symptoms, the number of women seeking consultation for issues relating to menopause is expected to be substantial. ${ }^{(3)}$

\section{SYMPTOMS OF MENOPAUSE}

Body ache is the most common symptom experienced by Asian women, ${ }^{(1,2,4)}$ followed by irritability and sleep disturbances. ${ }^{(1,2,4,5)}$ However, these symptoms can vary widely from country to country, even among Asians. Symptoms that have led many to seek medical assistance include sleeplessness, hot flushes, headache or migraine, mood swings and irritability.

\section{MANAGEMENT OF COMMON SYMPTOMS Hot flushes}

Hot flushes are typically short-lived, with each episode lasting from five to ten minutes. Hot flushes that last longer require further workup to exclude other causes such as hyperthyroidism, fever, rosacea, etc. ${ }^{(6)}$ Table I shows the grading of the severity of hot flushes. For mild and moderate symptoms, a trial of lifestyle measures would often improve the symptoms. These measures include exercise, dressing in lighter clothing, sleeping in a cooler room, dressing in layers, stress reduction with mind-body and
Table I. Severity of hot flushes and its management.

\begin{tabular}{lll}
\hline Severity & Symptoms & Management \\
\hline Mild & $\begin{array}{l}\text { Sensation of heat without } \\
\text { sweating }\end{array}$ & Lifestyle management \\
Moderate & $\begin{array}{l}\text { Sensation of heat with } \\
\text { sweating, able to continue } \\
\text { activity }\end{array}$ & $\begin{array}{l}\text { Trial of lifestyle } \\
\text { management. Hormone } \\
\text { therapy if lifestyle } \\
\text { measures fail }\end{array}$ \\
Severe & $\begin{array}{l}\text { Sensation of heat with } \\
\text { sweating, causing } \\
\text { cessation of activity }\end{array}$ & $\begin{array}{l}\text { Lifestyle management and } \\
\text { consider hormone therapy } \\
\text { after weighting the risks } \\
\text { and benefits }\end{array}$ \\
\hline
\end{tabular}

Adapted from www.fda.gov/downloads/Drugs/DrugSafety/Informationby DrugClass/UCM135338.pdf.(7)

relaxation therapies. ${ }^{(8)}$ Women with severe symptoms or who do not see improvement with lifestyle management may consider hormone therapy, which is the gold standard in treatment, after weighing the risks and benefits to the patient. ${ }^{(9)}$ Currently, there is a lack of evidence that bioidentical hormones are safer and more efficacious than conventional hormone therapy. The variability in drug bioavailability and bioactivity can pose additional risks to users. ${ }^{(10)}$ Alternative treatments for patients with contraindications include selective serotonin reuptake inhibitors (SSRIs), serotoninnorepinephrine reuptake inhibitors (SNRIs) and clonidine. Vitamin E and black cohosh have been widely used as an overthe-counter drug, but there is currently insufficient evidence that they are useful for women with menopausal symptoms. ${ }^{(11,12)}$ Phyto-oestrogens have yielded inconsistent results, and the potential risks of endometrial hyperplasia over a prolonged period of use is a concern. ${ }^{(13,14)}$

\section{Sleep issues during menopause}

Menopausal transition does not cause sleep disturbances, ${ }^{(15)}$ but women with severe vasomotor symptoms have been found to experience significant sleep disturbances. ${ }^{(16,17)}$ Work stress

${ }^{1}$ Family Medicine Service/Menopause Unit, KK Women's and Children's Hospital, ${ }^{2}$ Singhealth Polyclinic - Sengkang, Singapore

Correspondence: Dr Ang Seng Bin, Consultant and Head, Family Medicine Service/Menopause Unit, KK Women's and Children's Hospital, 100 Bukit Timah Road, Singapore 229899. angsengbin@gmail.com 


\begin{tabular}{|c|c|c|c|c|c|}
\hline & Age 40-44 & 45-49 & 60-64 & 65-69 & $>75$ \\
\hline Hypertension & \multicolumn{5}{|c|}{$\begin{array}{l}\text { Every } 2 \text { yrs if DBP below } 85 \mathrm{mmHg} \text { and SBP below } 130 \mathrm{mmHg} \\
\text { Yearly if DBP } 85-89 \mathrm{mmH} \text { or SBP of } 130-139 \mathrm{mmHg}\end{array}$} \\
\hline Fasting Lipids & \multicolumn{5}{|c|}{ Fasting lipids once every 3 years or more frequently when indicated } \\
\hline Obesity & \multicolumn{5}{|c|}{ Assess Body Mass index and waist circumference yearly } \\
\hline Diabetes Mellitus & \multicolumn{5}{|c|}{ Fasting Glucose every 3 years } \\
\hline Visual Acuity & & & \multicolumn{3}{|c|}{ Snellen Chart } \\
\hline Colorectal Cancer & & & \multicolumn{3}{|c|}{$\begin{array}{l}\text { Annual Faecal Occult Blood Test, or flexible sigmoidoscopy } 5 \text { yearly or } \\
\text { colonoscopy once every } 10 \text { years }\end{array}$} \\
\hline Renal Disease & \multicolumn{5}{|c|}{ Opportunistic screening with urine dipstick } \\
\hline Cervical Ca & \multicolumn{4}{|c|}{$\begin{array}{l}\text { Pap smear once every } 3 \text { years in woman who have ever had } \\
\text { sexual intercourse }\end{array}$} & \\
\hline $\begin{array}{l}\text { Breast Ca } \\
\text { Asymptomatic }\end{array}$ & \multicolumn{5}{|c|}{$\begin{array}{l}\text { Inform women of risk vs } \\
\text { benefits. If screening desired do } 2 \text { years } \\
\text { annual Mammogram }\end{array}$} \\
\hline On HRT & \multicolumn{5}{|c|}{ From commencement of HRT till 5 years after stopping. Follow screening intervals of other woman } \\
\hline Osteoporosis & & & & \multicolumn{2}{|c|}{$\begin{array}{l}\text { Bone mineral density measurement. Earlier if } \\
\text { other risk factors exist or high risk or moderate } \\
\text { risk with risk factors on OSTA. Not indicated in } \\
\text { premenopausal women without risk factors. }\end{array}$} \\
\hline
\end{tabular}

Fig. 1 Health screening recommendations for women. Adapted from Ministry of Health, Singapore Clinical Practice Guidelines for Health Screening July $2003^{(20)}$ and Clinical Guidelines for Cancer Screening February 2010.(21)

can also exacerbate sleep issues. ${ }^{(18)}$ Initial management of sleep disturbances should consist of lifestyle management and sleep hygiene. Patients should avoid excessive intake of caffeine and alcohol, and create a conducive sleep environment by avoiding activities such as surfing the Internet and watching television programmes in the bedroom.

\section{Female sexuality issues after menopause}

The number and severity of sexuality issues increase as the years progress post menopause. The causes are usually multifactorial. A holistic assessment includes a complete sexual, medical and psychosocial history-taking, followed by physical examination. Optimal management of sexuality problems requires the active participation of the patient's partner. Measures to improve psychological well-being and intimacy, as well as avoidance of medications and substances that can aggravate vaginal dryness, are important. The use of vaginal lubricants in women with vaginal dryness is also useful. In cases where vaginal lubricants fail to help, topical oestrogen may be considered. However, it is important to note that higher doses of topical oestrogen will result in systemic oestrogen absorption and carry associated risks. ${ }^{(19)}$

\section{HOLISTIC ASSESSMENT OF MENOPAUSAL WOMEN}

Menopause is an opportune time in life where family physicians can play an important role in maximising the quality of life of women in their later years. This would include the: (a) prevention of diseases by encouraging women to adopt a healthy lifestyle (balanced diet, weight-bearing exercises and avoidance of harmful substances like tobacco) and undergo vaccinations (influenza/pneumococcal vaccines in the vulnerable and herpes zoster vaccines); (b) early detection of diseases by instituting regular screening for chronic diseases such as hypertension, diabetes mellitus and hyperlipidaemia, as well as cancers such as cervical and colon cancers (Fig. 1); (c) treatment of chronic diseases to target recommendation to reduce morbidity and mortality; and (d) recognition of life events in women that may occur around their early fifties, including stresses at the peak of their careers, independence of children and financial management for their approaching retirement.

You work with Madam Tan to identify the symptoms associated with perimenopause. She is relieved to know that her hot flushes are not multiple heart attacks. You highlight that she should not keep her smartphone by her bedside to access her work emails when she has difficulties sleeping. You also recommend that Madam Tan have a heart to heart talk with her daughter regarding her feelings of ambivalence over her daughter's recent engagement plans. Madam Tan thanks you for the holistic consultation.

\section{CONCLUSION}

Menopause is a natural stage in life that all women will go through. Most women do not encounter any major issues during menopausal transition. This is also an important milestone in a woman's life where she can take stock of her health, adopt a healthy lifestyle and live life to the fullest.

\section{TAKE HOME MESSAGES}

1. Menopause is a natural process that all women will go through.

2. Menopause is determined retrospectively, and laboratory tests are only required to exclude secondary causes.

3. Hot flushes that last significantly longer than 5-10 minutes may require further workup to exclude secondary causes. 
4. Hormone therapy for severe hot flushes is the gold standard, but the course and its risks and benefits must be agreed upon by the patient.

5. Currently, there is a lack of evidence that bioidentical hormones are safer and more efficacious than conventional hormone therapy.

6. Phyto-oestrogens have yielded inconsistent results, and the potential risk of endometrial hyperplasia over a prolonged period of use is a concern.

7. Sexuality issues are usually multifactorial and increase in number and severity as the years progress post menopause. Optimal management requires the active participation of the patient and her partner.

8. Holistic management at this stage includes the recognition of self, family, work and the patient's physical and mental well-being.

ABSTRACT Menopause, a natural process in a woman's life, is defined as the cessation of menstrual period for 12 consecutive months. In Singapore, the average age of natural menopause is 49 years of age. We discuss the challenges faced by menopausal women and provide an example of a holistic approach to the management of women during this important stage of their lives.

Keywords: hormone replacement therapy, menopause, women health Singapore Med J 2013; 54(2): 60-63

\section{REFERENCES}

1. Loh FH, Khin LW, Saw SM, Lee JJ, Gu K. The age of menopause and the menopause transition in a multiracial population: a nation-wide Singapore study. Maturitas 2005; 52:169-80.

2. Chim H, Tan BH, Ang CC, et al. The prevalence of menopausal symptoms in a community in Singapore. Maturitas 2002; 41:275-82.

3. Department of Statistics Singapore. Population Trends 2012 [online]. Available at: www.singstat.gov.sg/pubn/popn/population2012b.pdf. Accessed February 5, 2013

4. Haines CJ, Xing SM, Park KH, Holinka CF, Ausmanas MK. Prevalence of menopausal symptoms in different ethnic groups of Asian women and responsiveness to therapy with three doses of conjugated estrogens/ medroxyprogesterone acetate: the Pan-Asia Menopause (PAM) study. Maturitas 2005; 52:264-76.

5. Huang KE, Xu L, I NN, Jaisamrarn U. The Asian Menopause Survey: knowledge, perceptions, hormone treatment and sexual function. Maturitas 2010; 65:276-83.

6. Izikson L, English JC 3rd, Zirwas MJ. The flushing patient: differential diagnosis, workup, and treatment. J Am Acad Dermatol 2006; 55:193-208. Review.

7. Guidance for Industry - Estrogen and Estrogen/Progestin Drug Products to Treat Vasomotor Symptoms and Vulvar and Vaginal Atrophy Symptoms Recommendations for Clinical Evaluation [online]. Available at: www.fda. gov/downloads/Drugs/DrugSafety/InformationbyDrugClass/UCM135338. pdf. Accessed January 28, 2013.

8. Innes KE, Selfe TK, Vishnu A. Mind-body therapies for menopausal symptoms: a systematic review. Maturitas 2010; 66:135-49.

9. Santen RJ, Allred DC, Ardoin SP, et al. Postmenopausal hormone therapy: an Endocrine Society scientific statement. J Clin Endocrinol Metab 2010; 95(7 Suppl 1):s1-s66.

10. American College of Obstetricians and Gynecologists Committee on Gynecologic Practice; American Society for Reproductive Medicine Practice Committee. Compounded bioidentical menopausal hormone therapy. Fertil Steril 2012; 98:308-12.

11. Leach MJ, Moore V. Black cohosh (Cimicifuga spp.) for menopausal symptoms. Cochrane Database Syst Rev 2012; 9:CD007244.

12. Rada G, Capurro D, Pantoja T, et al. Non-hormonal interventions for hot flushes in women with a history of breast cancer. Cochrane Database Syst Rev 2010; 9:CD004923.

13. Unfer V, Casini ML, Costabile L, et al. Endometrial effects of long term treatment with phytoestrogens: a randomized, double-blind, placebocontrolled study. Fertil Steril 2004; 82:145-8.

14. Palacios S, Pornel B, Vázquez F, et al. Long-term endometrial and breast safety of a specific, standardized soy extract. Climacteric 2010; 13:368-75.

15. Young T, Rabago D, Zgierska A, Austin D, Laurel F. Objective and subjective sleep quality in premenopausal, perimenopausal and postmenopausal women in the Wisconsin Sleep Cohort Study. Sleep 2003; 26:667-72.

16. Pien GW, Sammel MD, Freeman EW, Lin H, DeBlasis TL. Predictors of sleep quality in women in the menopausal transition. Sleep 2008; 31:991-9.

17. Blümel JE, Cano A, Mezones-Holguín E, et al. A multinational study of sleep disorders during female mid-life. Maturitas 2012; 72:359-66.

18. Lampio L, Saaresranta T, Polo O, Polo-Kantola P. Subjective sleep in premenopausal and postmenopausal women during workdays and leisure days: a sleep diary study. Menopause 2013 Jan 14 [Epub ahead of print].

19. Goldstein I, Alexander JL. Practical aspects in the management of vaginal atrophy and sexual dysfunction in perimenopausal and postmenopausal women. J Sex Med 2005; 2 Suppl 3:154-65.

20. Ministry of Health Singapore. Clinical Practice Guidelines for Health Screening. July 2003.

21. Ministry of Health Singapore. Clinical Guidelines for Cancer Screening. February 2010. 


\section{SINGAPORE MEDICAL COUNCIL CATEGORY 3B CME PROGRAMME}

\section{(Code SMJ 201302A)}

1. About $50 \%$ of women will go through menopause.

2. Menopause can be predicted by follicle stimulating hormone/lutenising hormone 14 days after menses at 49 years of age in Singapore.

3. Menopause is determined retrospectively after 12 consecutive months of the cessation of menstrual period.

4. The use of laboratory tests in the diagnosis of menopause is mainly to exclude secondary causes.

5. Hot flushes that last for 30 minutes are atypical and require further workup.

6. Hormone therapy is no longer indicated for the treatment of severe hot flushes after the Women Health Initiative study.

7. There is no risk involved in hormone therapy in the management of menopause.

8. Alternative treatments for those with contraindications to hormone therapy include selective serotonin reuptake inhibitors, serotonin-norepinephrine reuptake inhibitors and clonidine.

9. Vitamin E and black cohosh have been widely used as over-the-counter drugs, but there is currently insufficient evidence to indicate that they are useful for women with menopausal symptoms.

10. Bioidentical hormones are safer than conventional hormone therapy.

11. Bioidentical hormones are more efficacious than conventional hormone therapy.

12. Phyto-oestrogens are a safer alternative to hormone therapy and are at least equally efficacious.

13. There is no risk of endometrial hyperplasia with prolonged use of phyto-oestrogen, and it is thus unnecessary to monitor its use in patients.

14. The number and severity of sexuality issues are usually multifactorial and increase as the years progress post menopause.

15. The management of sexuality issues in menopause requires the active participation of the patient and her partner.

16. Encouraging a balanced diet, weight-bearing exercises and vaccinations such as influenza and pneumoccoal vaccines are important in the holistic management of women in the menopausal age group.

17. Early detection of chronic diseases such as hypertension, diabetes mellitus and hyperlipidaemia through regular screening is recommended.

18. Screening for breast, cervical and colon cancers is recommended for women in this age group.

19. Life events occurring after the early fifties may result in stresses that can affect performance and sleep in women.

20. Other significant life events among women of this age group may include stresses at the peak of their careers, independence of children and financial management for their approaching retirement.

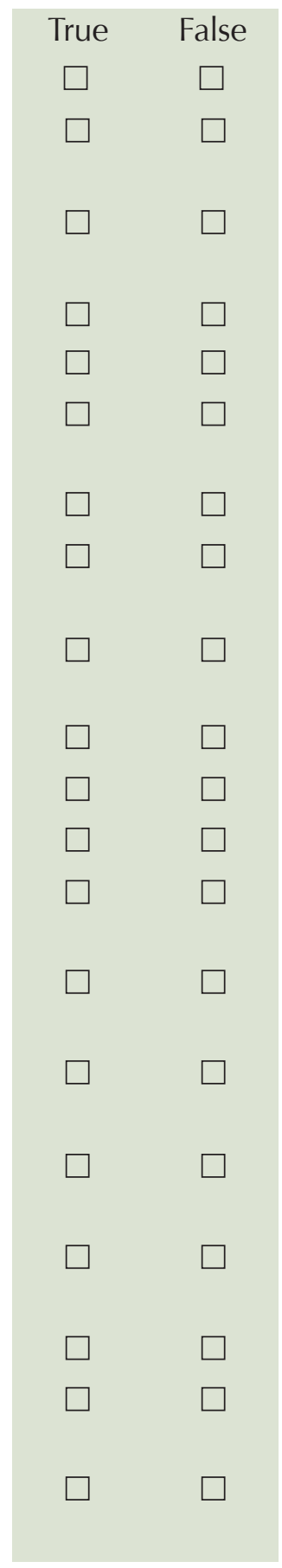

\section{Doctor's particulars:}

Name in full

MCR number

Specialty:

Email address

\section{SUBMISSION INSTRUCTIONS:}

(1) Log on at the SMJ website: http://www.sma.org.sg/publications/smjcurrentissue.aspx and select the appropriate set of questions. (2) Provide your name, email address and MCR number. (3) Select your answers and click "Submit".

\section{RESULTS:}

(1) Answers will be published in the SMJ April 2013 issue. (2) The MCR numbers of successful candidates will be posted online at the SMJ website by 1 April 2013 (3) Passing mark is $60 \%$. No mark will be deducted for incorrect answers. (4) The SMJ editorial office will submit the list of successful candidates to the Singapore Medical Council. (5) One CME point is awarded for successful candidates.

Deadline for submission: (February 2013 SMJ 3B CME programme): 12 noon, 25 March 2013. 